\title{
A comparison of Danish listeners' processing cost in judging the truth value of Norwegian, Swedish, and English sentences
}

\author{
Ocke-Schwen Bohn ${ }^{1,2}$, Trine Askjær-Jørgensen ${ }^{1}$ \\ ${ }^{1}$ Department of English, Aarhus University, Denmark \\ ${ }^{2}$ Center on Autobiographical Memory Research, Dept. of Psychology, Aarhus University, Denmark \\ ocke.bohn@cc.au.dk, trine.askjaer@gmail.com
}

\begin{abstract}
The present study used a sentence verification task to assess the processing cost involved in native Danish listeners' attempts to comprehend true/false statements spoken in Danish, Norwegian, Swedish, and English. Three groups of native Danish listeners heard 40 sentences each which were translation equivalents, and assessed the truth value of these statements. Group 1 heard sentences in Danish and Norwegian, Group 2 in Danish and Swedish, and Group 3 in Danish and English. Response time and proportion of correct responses were used as indices of processing cost. Both measures indicate that the processing cost for native Danish listeners in comprehending Danish and English statements is equivalent, whereas Norwegian and Swedish statements incur a much higher cost, both in terms of response time and correct assessments. The results are discussed with regard to the costs of inter-Scandinavian and English lingua franca communication.
\end{abstract}

Index Terms: Cross-language intelligibility, processing cost, inter-Scandinavian communication, lingua franca English

\section{Introduction}

The motivation for the present study stems from the fact that the languages that can be used as a medium of instruction in Scandinavian institutions of higher education are Danish, Norwegian and Swedish, as well as English. This study examines the processing cost involved in native Danish listeners' attempts to understand simple sentences produced in these four languages, thereby also testing the claim of the Nordic Council, an official inter-parliamentary body with members from Denmark, Finland, Iceland, Sweden, and Norway, that "Danish, Norwegian and Swedish are so closely related that if you speak one of them, relatively little effort is required to understand the others" [1]. Although these three languages are very closely related and share a large number of cognates in their lexica, research nevertheless suggests that Inter-Scandinavian intelligibility is not as good as the Nordic Council claims [2, 3, 4, 5]. Furthermore, even though schoolage Danes, Swedes, and Norwegians have some obligatory instruction in the other Scandinavian languages, this instruction is minimal, and they do not have much exposure to the other Scandinavian languages in everyday life [6]. In contrast, Scandinavians are instructed in English at school from a very young age (in Denmark now from the 1st grade), which makes it likely that they understand English more effortlessly than they do the neighboring Scandinavian languages.

The aim of the present study was to examine the relative processing difficulty that native Danish speakers encounter when they attempt to comprehend either Norwegian, Swedish, or English utterances, as compared to their native language. The index of processing difficulty that we chose was native Danish listeners' latency in assessing the truth value of simple true or false utterances presented in Norwegian, Swedish, and English as opposed to the native language, Danish. As an additional measure of processing difficulty we used the proportion of correct responses to these simple true or false statements. Together, differences in the response latency and proportion of correct responses to Danish, which served as the baseline, as opposed to nonnative utterances provide a measure of the processing cost incurred in trying to comprehend the nonnative languages.

A heightened processing cost as revealed by longer response times or a decrease in intelligibility can be due to factors associated either with the signal (e.g., unfavorable signal/noise ratio, reduced bandwidth), or to listener characteristics such as hearing impairment or lack of familiarity with the language or language variety that constitutes the signal. Several previous studies have shown that listening to a different regional native accent or to foreign accented speech incurs a processing cost in terms of longer response times. For instance, Floccia et al. [7] reported that native French listeners had longer lexical decision latencies for targets placed at the end of sentences with different French regional accents. Munro \& Derwing [8] compared the response time which native English listeners needed to verify English sentences produced by native English speakers and by native Mandarin speakers. They reported that "Mandarinaccented utterances required more time to evaluate than the utterances of native English speakers.”

The present study was inspired by the Munro \& Derwing [8] study. However, instead of comparing the processing cost for different native and nonnative accents of one language, we examined the cost involved in trying to understand native language (Danish) utterances as compared to the nonnative languages Norwegian, Swedish, and English. The present cross-language study employed a similar design and largely identical stimulus sentences as the Munro \& Derwing [8] study. The measures of comprehension difficulty used in the present study are the response time needed by listeners to assess the truth value of straightforwardly true or false sentences, as well as their success in assessing the truth value correctly.

\section{Methods}

\subsection{Participants}

Three groups of native Danish listeners participated as unpaid volunteers. All 53 participants were current or former 
university students from Aarhus University except for two participants who had a different educational background. The participants had normal hearing, Danish as a native language, and had not been exposed to languages other than Danish during childhood. 32 listeners (24f, $8 \mathrm{~m}, \mathrm{M}_{\mathrm{age}}=24.9$ years) were randomly assigned to the Norwegian or the Swedish experiment (16 listeners each). These participants are representative of young Danish adults in that they had limited knowledge of Swedish and Norwegian, which for this generation includes minimal obligatory instruction in both languages in grade school and in high school. The 21 listeners (16f, 5m, $\mathrm{M}_{\text {age }}=24.2$ years) who heard English sentences were exposed to English on a daily basis as part of their studies and can thus be considered representative of a large proportion of Danish university students. Seventeen of the 21 listeners had not spent more than 2 months in an Englishspeaking country, and the results from the 4 participants in this group who had spent up to 2 years in an English-speaking country did not differ in any noticeable way from the rest of the group.

\subsection{Speech materials}

The 20 true and 20 false sentences used in the present study were identical to the list of sentences used in the Munro \& Derwing study [8], with three exceptions. ${ }^{1}$ These 40 sentences are either very obviously true (e.g., "Red and green are colors") or false (e.g., "All dogs have fifteen legs"). The sentences were translated into Danish, Swedish, and Norwegian by highly English-proficient native speakers of these languages, and recorded by one native speaker of each of these languages, as well as by a native speaker each of Southern British English and General American. An additional set of 10 sentences ( 5 true, 5 false, translation equivalents in the four languages) was recorded by a different set of speakers for listener familiarization. The recordings were made in a sound-treated facility using high-fidelity digital equipment. All sentences were produced at a normal speaking rate for reading text, and any recordings containing dysfluencies, voice or rate irregularities were re-recorded until the experimenter (one of the authors) was satisfied with the quality. The sentences were segmented from the recordings and individually normalized for peak intensity.

\subsection{Procedure}

We conducted three between-group experiments in which the listeners heard either Danish and Norwegian sentences (Experiment 1), or Danish and Swedish (Experiment 2) or Danish and English sentences (Experiment 3). The sentences were presented over headphones from a laptop computer using the praat [9] stimulus presentation module. Instructions were given in Danish, orally as well as on the computer screen, which also displayed two boxes with the Danish labels "rigtigt" (true) and "forkert" (false). Participants were instructed to place their dominant hand so that the index and the middle finger covered the " $\mathrm{N}$ " and " $\mathrm{M}$ " keys on the keyboard, which registered a "true" (for "N") or a "false (for "M") response. Listeners were instructed to respond as fast and as accurately as possible. There was a $1.0 \mathrm{~s}$ delay between the response and the presentation of the next sentence.

Each listener heard 20 Danish sentences and 20 sentences in one of the nonnative languages. The sequence in which listeners heard the Danish or the nonnative sentences was counterbalanced so that one half of the listeners in each experiment heard 20 Danish sentences first and 20 sentences in the nonnative language second, and half of the listeners heard the nonnative sentences before the Danish sentences. The sequence of sentences in the three experiments was also counterbalanced within each subgroup. For example, in Experiment 1, 8 listeners heard Danish sentences first, and 8 listeners heard Norwegian sentences first. Four listeners in each of these subgroups heard sentences 1-20 first, followed by sentences 21-40, and 4 listeners heard sentences 21-40 first, followed by sentences 1-20. Independent-samples t-tests conducted for each experiment revealed that neither the order of language presentation (Danish sentences first or second) nor the order of sentence presentation affected the response time or the number of correct responses, $\mathrm{p}>.2$.

Each sequence of 20 sentences was preceded by 10 familiarization sentences which were not used in the further analysis of the responses. These 10 sentences were in the same language as the following 20 sentences, but were recorded from different speakers reading translation equivalents of the same list of sentences in Danish, Norwegian, Swedish, and English, e.g., "It can get very hot in the desert" and "Each year has two thousand days."

The participants who heard the English and Danish sentences were asked whether their target accent was American English or Southern British English. Depending on their response, they heard sentences recorded from a native speaker of General American or Southern British English. The text for the English sentences was identical except for the first sentence, in which the American speaker read the word "gasoline", and the British speaker, "petrol” in the sentence " $\mathrm{X}$ is an excellent drink".

\section{Results}

Figure 1 shows the mean response times, measured from the end of the stimulus sentences, for the Danish, Norwegian, Swedish, and English sentences to which the listeners had correctly responded. The figure shows a clear difference between the response times for Danish and English sentences $(<1 \mathrm{sec})$ on the one hand, and the Norwegian and Swedish sentences on the other $(>1 \mathrm{sec})$.

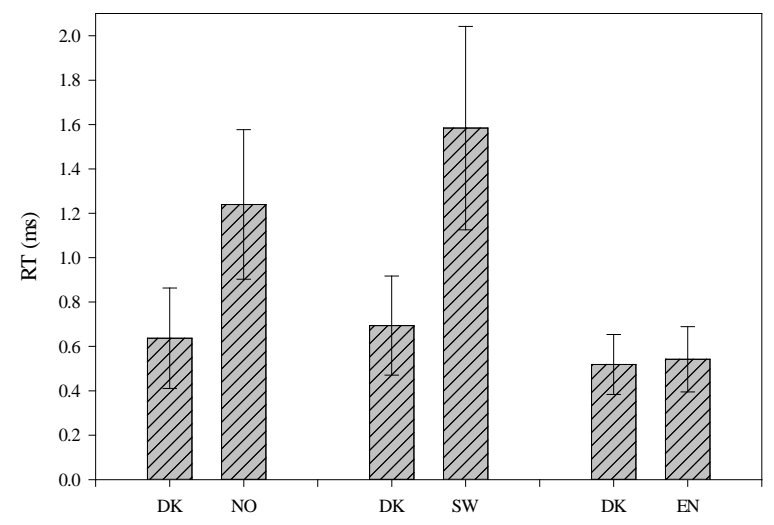

Figure 1: Mean response times (in $\mathrm{ms}$ ) for the assessment of truth values to sentences presented in Danish (DK), Norwegian (NO), Swedish (SW), and English (EN). Error bars represent +/- $1 S D$. 
Figure 2 shows the mean number of correct responses to sentences presented in Danish, Norwegian, Swedish, and English. This figure shows that the number of correct responses to Danish and English sentences was at or near the ceiling of 20, whereas the number of correct responses to Norwegian and Swedish sentences was clearly reduced.

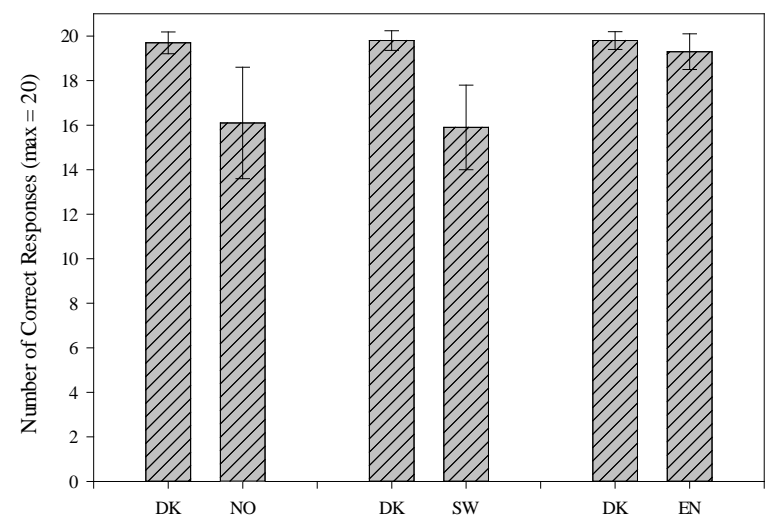

Figure 2: Number of correct responses (out of 20) in the assessment of truth values to sentences presented in Danish (DK), Norwegian (NO), Swedish (SW), and English (EN). Error bars represent +/- 1 SD.

Three sets of paired t-test were conducted to compare the response times for Danish sentences and Norwegian sentences (set 1), for Danish and Swedish sentences (set 2), and for Danish and English sentences (set 3). For the statistical comparison of the number of correct responses, paired t-tests were attempted and, when the prerequisites for a parametric test were not met, we applied Wilcoxon Signed Rank tests.

For the Danish-Norwegian comparison, there was a significant difference in the mean response times for Danish sentences $(\mathrm{M}=0.64 \mathrm{~s}, \mathrm{SD}=0.22)$ and for Norwegians sentences $(\mathrm{M}=1.24 \mathrm{~s}, \mathrm{SD}=0.34) ; \mathrm{t}(15)=-10.304, \mathrm{p}<0.001$. The paired $\mathrm{t}-$ test revealed that the number of correct responses to Danish sentences ( $M=19.7, S D=0.5$, range $19-20)$ was significantly higher than the number of correct responses to Norwegian sentences $(M=16.1, S D=2.5$, range 14-20) $t(14)=5.233, p>$ .001 .

For the Danish-Swedish comparison, there was a significant difference in the mean response times for Danish sentences $(M=0.69 \mathrm{~s}, \mathrm{SD}=0.14)$ and for Swedish sentences $(\mathrm{M}=1.58 \mathrm{~s}, \mathrm{SD}=0.40) ; \mathrm{t}(15)=-11.437, \mathrm{p}<.001$. A paired ttest revealed that the number of correct responses to Danish sentences $(M=19.8, S D=0.4$, range $19-20)$ was significantly higher than the number of correct responses to Swedish sentences $(M=15.9, S D=1.9$, range 14-19); $t(12)=8.276, p$ > .001 .

For the Danish-English comparison, the difference in the mean response times for Danish sentences $(\mathrm{M}=0.52 \mathrm{~s}$, $\mathrm{SD}=0.14)$ and for English sentences $(\mathrm{M}=0.54 \mathrm{~s}, \mathrm{SD}=0.15)$ did not differ significantly; $t(20)=-0.716, p=.482$. However, a Wilcoxon Signed Rank test revealed that the number of correct responses to Danish sentences ( $M=19.8, \quad S D=0.4$, range 19-20) was significantly different from the number of correct responses to English sentences $(\mathrm{M}=19.3, \mathrm{SD}=0.85$, range 17-20), $\mathrm{Z}=-2.33, \mathrm{p}<.05$.

Two additional between-subjects ANOVAs compared the response times and the number of correct responses for the nonnative languages. The two Kruskal-Wallis ANOVAs on ranks for these two dependent variables were significant ( $\mathrm{p}<$ .001). Pairwise multiple comparisons (Dunn's method) revealed that the response times to Swedish and to Norwegian sentences did not differ significantly, but that the responses to English sentences were significantly faster than to the Norwegian and Swedish sentences $(\mathrm{p}<.05)$. The same pattern of results was obtained for the number of correct responses (no significant differences between Norwegian and Swedish sentences, and a significantly higher number of correct responses to English than to both Norwegian and Swedish responses, $\mathrm{p}<.05$ ).

Summarizing the results, the participants in the present study processed simple true/false statements equally fast when these statements were presented in the native language, Danish, and in the nonnative language English. Sentences presented in Norwegian or Swedish, however, were processed at a significantly slower rate. The pattern for the proportion of correct responses mirrored the pattern for the response time, with Danish and English sentences being processed correctly at or near ceiling, whereas almost $25 \%$ of the translation equivalents presented in Norwegian and Swedish were incorrectly processed, suggesting that these sentences were incomprehensible for native Danish listeners. Overall, these results suggest that native Danish listeners pay a much higher processing cost when trying to comprehend Norwegian and Swedish, than Danish and English.

\section{Discussion}

The present study examined the processing cost involved in native Danish listeners' attempts to comprehend simple true/false sentences produced in Danish, Norwegian, Swedish and English. The indices of processing cost used in this study were the time needed by listeners to judge the truth value of these auditorily presented sentences (response time), as well as the number of correctly judged sentences. In each of three experiments, listeners heard Danish sentences as well as sentences in one of the nonnative languages. Thus, Danish served as the baseline for these comparisons since it was the participants' native language and results from processing Danish sentences represented the best possible results participants could obtain.

The results showed that participants were fastest to respond and provided the largest number of correct answers when listening to Danish sentences. Interestingly, English was processed equally fast (the reaction times for Danish and English sentences were both $<1 \mathrm{sec}$ ) and the number of correct responses for English was near ceiling. Although the nonparametric signed rank test comparing the number of correct responses for Danish and English sentences yielded a statistically significant result, the difference in mean values was quite small (19.8 vs. 19.3 out of 20).

Moreover, the results showed that participants responded significantly slower (> $1 \mathrm{sec}$ for Swedish and Norwegian) and provided a significantly smaller number of correct responses when listening to Swedish and Norwegian as compared to English and Danish. Both the Danish-Norwegian and DanishSwedish comparisons showed significantly faster mean 
response times and higher number of correct responses for Danish as compared to Norwegian and Swedish sentences. The between-subjects tests for response times and number of correct responses across the three non-native languages revealed that there was no significant difference in our measures of processing cost for the Swedish and Norwegian sentences, whereas the English sentences were processed with significantly less effort (in terms of faster response times and higher number of correct responses).

The present study was partly motivated by an interest in assessing whether communication in any of the three North Germanic languages in member countries of the Nordic Council is as uncomplicated as has been claimed [1]. Our results do not support this claim. With respect to interScandinavian communication/intelligibility, our results specifically showed a clear difference between native Danish listeners' processing of Swedish and Norwegian on the one hand, and Danish and English on the other. As expected, Danish was apparently effortlessly processed whereas processing both Swedish and Norwegian involved much more effort, which was evident in the considerably longer response times and in the clearly reduced number of correct responses. English, however, was processed just as fast and nearly as accurately as Danish. The results of the present study suggest that native Danish speakers' processing cost in interScandinavian communication is considerably higher than the cost involved in their processing of English, which is the world's lingua franca and which Danes are massively exposed to in the media and in their education, starting in grade school as an object of instruction and frequently also as a medium of instruction in higher education.

The conclusion drawn from the present study on the relative processing cost for native Danish listeners in trying to comprehend Norwegian, Swedish, and English needs to be qualified by acknowledging that the experiments reported here are not truly ecologically valid. Communication is typically supported by both linguistic and extra-linguistic context, whereas the sentences presented here were "stand-alone", with no such context. Still, our result that the processing of very clearly true or false sentences was substantially more costly for Norwegian and Swedish than for Danish and English sentences suggests that inter-Scandinavian communication, with Danish listeners at the receiving end, takes up considerable cognitive resources.

The present study is part of a larger project which also examines, for each utterance, the relation between subjective comprehensibility ratings on the one hand, and the response time and correct response on the other. The participants in the present study all took part in a second run (after the experiments reported here) in which they indicated, using a 9point Likert scale, how difficult each nonnative sentence was to understand. We expect that a comparison of these comprehensibility ratings to the response times and number of correct responses can first be used to determine which sentences were perceived to be difficult to comprehend and whether and how this subjective evaluation is related to the more objective measures (response time and correctness of response) reported here. Further fine-grained analyses will then provide an indication of whether differences in processing cost are due to lexical, morphosyntactic, or phonetic/phonological differences between Danish, Swedish, and Norwegian.
The present study was conducted with native Danish participants listening to Norwegian, Swedish, and English sentences. As a logical extension, we plan to conduct studies with the same experimental setup but with Norwegian and Swedish listeners to complement the present results and to determine whether inter-Scandinavian intelligibility is characterized by symmetrical or asymmetrical processing costs.

\section{Acknowledgements}

Research for this study was supported by grants from the Danish National Research Foundation (DNRF89), the Carlsberg Foundation, and Inge Lehmanns legat af 1983.

\section{Endnote}

${ }^{1}$ We changed the Munro \& Derwing's [8] false sentences "A nickel is worth 25 cents" and "The Queen of England lives in Washington" to "A dollar is worth seventy cents" and "The Queen of England lives in Baghdad”, and we replaced the true sentence "Shakespeare wrote many fine plays" with "Mozart was a great composer".

\section{References}

[1] The Nordic Council. "Nordic Co-operation". Internet: http://www.norden.org/en/fakta-om-norden-1/language [30.1. 2017].

[2] Øyvind Maurud. Nabospråksforståelse i Skandinavia: en Undersøkelse om Gjensidig Forståelse av Tale- og Skriftspråk i Danmark, Norge og Sverige. Stockholm: Skandinaviska Rådet, 1976.

[3] Inge Bø. Ungdom og Naboland. Stavanger: Rogalandsforskning (rapport 4), 1978.

[4] Ulla Börestam. Dansk-Svensk Språkgemenskap på Undantag. Uppsala: Uppsala Universitet, 1987.

[5] Katarina Lundin Åkesson. "Hur Väl Förstår Vi Varandra i Norden Idag?”. Språk i Norden, Nordisk Språkråd og Språknemdene i Norden, pp. 159-175, 2005.

[6] Charlotte Gooskens. "Linguistic and Extra-Linguistic Predictors of Inter-Scandinavia Intelligibility". Linguistics in the Netherlands vol. 23 (1), pp. 101-113, 2006.

[7] Caroline Floccia, Jeremy Goslin, Frederique Girard \& Gabrielle Knopczynski. "Does a Regional Accent Perturb Speech Processing?” Journal of Experimental Psychology: Human Perception and Performance vol. 32, pp. 1276-1293, 2006.

[8] M. J. Munro and T. M. Derwing "Processing Time, Accent and Comprehensibility in the Perception of Native and ForeignAccented Speech”. Language and Speech, vol. 38 (3), pp. 289306, 1995.

[9] Paul Boersma \& Weenink. Praat version 5.4.16. Internet: http://www.fon.hum.uva.nl/praat/download_win.html. [19.8.2016] 